\title{
Migratory Practices: introduction to an impossible place?
}

\author{
By Amanda Ravetz and Jane Webb
}

\begin{abstract}
Amanda Ravetz lives and works in Manchester and is a Research Fellow at MIRIAD, MMU. She has a PhD in Social Anthropology with Visual Media from the University of Manchester. Her interests cross-cut the fields of anthropology, film and contemporary art. She is currently drafting a book Rethinking Observational Cinema with her colleague Anna Grimshaw.

Jane Webb is a Senior Lecturer on the Contemporary Crafts degree programme at MMU Cheshire and a freelance writer concerning the crafts. She has a PhD in Design History and Material Culture from the University of Wolverhampton. She is interested in challenging the relationship between the written and practice and explores both visual and textual methods in her historical research.

Abstract: This essay serves as an introduction to five papers first presented at a conference held in the UK in 2006. Migratory Practices called on scholars and practitioners to report on crossings between the fields of anthropology, art, craft and design. The aim of the conference was to consider the under-acknowledged contribution of craft and design to the growing dialogue between contemporary anthropology and art.
\end{abstract}

In this essay we consider some of the discourses that surround the term 'practice'. We originally used 'practice' in our conference title to acknowledge a possible relationship between the merging of theory and action implicit in this term, and the newly explicit crossings between anthropology, art, design and craft. Here we look further into this relationship, while also asking what other assumptions about human beings, art and making have underpinned apparent differences between the four fields. Taking two historical moments, we suggest that in western contexts, shared assumption about what it means to be in, and act upon the world, have at various times, underlain all four fields. During the nineteenth century art, craft, anthropology and design each conceptualised the relationship between human beings and the material world using categories such as 'object', 'technology' and 'skill'. In the twentieth century, these categories were increasingly blurred through the development of more processual perspectives on how non-human and human worlds interrelate; and at the beginning of the twenty first century, we find a concern for organic notions of skilled practice emerging across all four domains.

Having established these historical connections, and after considering a number of concrete examples, we introduce the five papers. The projects they report on convey the rich insights that result when craft and design become active and visible participants in the art/anthropology debate. 


\section{Context}

Migratory Practices has its origins in a conference convened by Amanda Ravetz and Jane Webb at Manchester Metropolitan University (MMU) in September 2006. The conference title reflected our interest in exploring the practice-based movements between art, anthropology, design and craft. In convening the conference we did not want to suggest that boundaries between these areas should be dissolved, but rather to examine exchanges that highlight the merging of theory and action, signalled by the term 'practice'. The added metaphor of migration was intended to suggest that within a global intellectual context, there are innumerable ways in which makers' and academics' activities are developed and intertwined. Drawing on contemporary theories of geographical migration, we too sought to go beyond the dualities of stasis and movement, place and migration, highlighting instead then“...plurality of experiences, histories and constituencies" that direct what it means to migrate or be located. ${ }^{1}$

Earlier in 2006, whilst working in separate areas of the same institution ${ }^{2}$ we discovered that not only had we both studied anthropology at different points in our careers, but that we were both concerned with how theory and action come together through 'practice'. At the time Ravetz was working on a project modelling and testing an 'aesthetic' ethnography, drawing inspiration from examples of contemporary art. $^{3}$ For a brief time she had been a lecturer at Manchester University's Granada Centre for Visual Anthropology one of the few programmes in the UK to offer a visual media course centred on ethnographic filmmaking. Despite the emphasis on visual practice at GCVA, she had found the exclusive focus on ethnographic filmmaking inhibiting to the use of other visual media and methods. In 2004 she moved to the Manchester Institute for Research and Innovation in Art and Design (MIRIAD) to pursue alternative forms of visual enquiry and to explore how the methods and subjects of anthropological study might be fused through material forms other than ethnographic film.

Webb, alongside freelance work, was writing and running the material culture units of the MMU Cheshire Contemporary Crafts degree programme. This involved introducing students to theoretical issues in ways that would resonate positively with studio practice, a task hampered by the relative lack of critical writing about craft. She had also begun to develop materially-based ways of pursuing and communicating historical research. During her work establishing a programme for contemporary crafts students, she had become aware of the overlaps between makers', designers' and anthropologists' interests. Furthermore, it seemed important to acknowledge that alongside contemporary activities, craftspeople and designers had historically been deeply entangled

1 See Ahmed et al 2003:1-2.

2 Webb as a lecturer at MMU Cheshire, Ravetz as a research fellow at MIRIAD, MMU.

3 For a description of some of this work see Ravetz, A. 2007 "A weight of meaninglessness about which there is nothing insignificant': abjection and knowing in an art school and on a housing estate". In Harris, M. (eds.) Ways of Knowing? New Anthropological Approaches to Method, Learning and Knowledge, Berghahn, Oxford. 
with ethnographic research. In line with Ravetz's interests, Webb had observed the potential for visual practices to embody and expound anthropological critique.

The catalyst for the conference was Webb's involvement as critical writer on the Here and There project (HAT2) - a series of artists' exchanges offering residencies for artist-makers in South Asia, Australia and Britain. HAT2 had developed from an earlier residency programme aimed at jewellers from Britain and Australia and was therefore biased towards craft. A requirement of Webb's writing commission was to provide a forum for discussion of the critical implications of the cross-cultural residencies that formed part of HAT2. A conference seemed an appropriate form through which to do this.

\section{Framing the conference}

Until recently, there were two zones of contact between anthropology and visual practice - the museum, with the exhibition as the material form of exchange; and the cinema, centring on video and film (Bouquet 2001; Grimshaw 2001). In the last few years however, a third space has opened up. Writers have pointed to new links between contemporary art and anthropology, suggesting these might form the basis for an extension of anthropology's aesthetic and epistemological repertoire. ${ }^{4}$ But during this time little has been said about how craft and design fit in this conversation. Are these fields included under the category 'contemporary art' for the purposes of the art/anthropology debate? Or have they been conveniently ignored?

Craft in particular has played the role of 'other' to the fine arts and industrial design since at least the nineteenth-century (Adamson 2007:2). Because of this, we felt it too simplistic to simply substitute craft and design for art in the exchanges between anthropology and visual practice. In order to integrate craft and design into the debate, we invited three keynote speakers who could 'stand for' the different fields. ${ }^{5}$ To represent disciplinary positions as both firmly established and yet open to dialogue, we invited Moira Vincentelli, Tim Ingold and Roy Villevoye to provide points of reference around which our conception of 'migratory practices' could be explored.

Questions of practice have become central to recent discussions about art and anthropology. Tim Ingold has suggested that despite their different outcomes, both art and anthropology are exploratory knowledge practices, relying on inherently creative and perceptual ways of learning about the world. ${ }^{6}$ Arnd

4 See for example Marcus and Fischer 1986; Marcus and Myers 1995; Pink 2004; Grimshaw and Ravetz 2005; Schneider and Wright 2006; Ingold 2007; Grimshaw and Ravetz 2009.

5 As things turned out our call produced only one or two design-focused contributions and at this point we decided to reconsider our initial plans for four keynotes. We have retained the category of design in this essay, with a contribution from designer Hamid van Koten. We hope that our attempt to insert craft into the art/anthropology debate will soon be properly extended to design.

6 http://www.abdn.ac.uk/creativityandpractice/background.shtml 
Schneider and Christopher Wright (2006) also see art and anthropology as complimentary, though unlike Ingold, they argue that the convergence between them rests on the practices of appropriation each field has developed in order to negotiate culture and cultural difference. ${ }^{7}$

Our own use of the word 'practice' was intended to evoke these and other debates and to foreground the interconnectedness between making, knowing and communicating in all four fields. Inviting presentations under five headings, ${ }^{8}$ we sought contributions that would report directly on the migrations between art, anthropology, design and craft. By suggesting groupings that could apply to all subject areas, we hoped there would be scope for participants to illuminate the plurality of experiences that characterize crossings between the four fields.

\section{Questions of practice}

As we looked more closely at the way the relationship between human beings and the material world have been engaged with in each field, we began to see connections between these different discourses, giving us new perspectives on our own and others' cross-disciplinary work. What follows is an evocation of two 'moments' we have discerned in what, at times, have seemed to be the parallel trajectories of anthropology, art, craft and design. In exploring these, and in the subsequent section that looks at contemporary examples of practice, ${ }^{9}$ our intention is to suggest the rich contextual landscape from which the papers emerge.

Our first 'moment' focuses on a period between 1830 and 1890. In Britain the mechanisation of industry had reached its peak. A number of writers, artists and anthropologists responded to these changes by considering the possibilities of a return to a simpler relationship between making, production and people. While those interested in craft focused on what was happening in Britain, the nascent discipline of anthropology turned its attention to discovering the 'origins of mankind' in geographically and culturally remote sites. But despite choosing different locations and timeframes, craft theorists and anthropologists shared a conviction that material objects held the key to schematising - and manipulating - technological and social progress.

The second moment takes us forward by almost one hundred years to the 1950s, 1960s and 1970s, when practice began to be theorised as something independent of the technological manipulation of material. The visual arts,

7 "Appropriation should be re-evaluated as a hermeneutic procedure - an act of dialogical understanding - by which artists and anthropologists negotiate access to, and traffic in, cultural differences" (Schneider 2006:36).

8 The five headings were 'extending the art/anthropology debate'; 'fieldworks', 'making and ethnography'; 'ethics' and 'crossing borders'.

9 Despite wanting to include craft and design alongside art, both at the conference and in this collection, we faced a problem that the majority of contributions were from those defining themselves as artist-makers. Fine art thus slips in and out of view in this essay. 
sociological and anthropological theory began to consider the practices of everyday life - for example cooking, walking and eating - as things of interest in their own right. Some even suggested that these overlooked habits could be seen as modes of resistance in an unprecedented era of consumption (Highmore 2002: 6-13). Practice came to be considered an independent principle, one distinguishable from, though connected to, the materiality of the world.

\section{Moment One}

In 1834 Augustus W. Pugin set forth two visions of the relationship between everyday life and architectural practice (Pugin 1969: appendix illustrations). The first was a medieval society with its associated feudal economies and socially supportive, small-scale communities - symbolised by a hands-on craftbased aesthetic. The second evoked a modern industrial society, dominated by centralised schemes for controlling a population. This was epitomised by the anonymous design of the minimal and mass-produced factory building. By contextualising his craft-centred manifesto in this way, Pugin drew an analogy between the qualities associated with types of making and forms of living, a relationship that was to be actively pursued by William Morris and Charles Ashbee among others (Lambourne 1980: 9).

Morris's ambition in founding the firm of Morris, Marshall, Faulkner \& Company in 1861 was to focus on the decorative arts, particularly as they could be applied in architecture (ibid 1980: 18). Central to his philosophy was the idea that by reclaiming individuated production in this area of design, the alienation of the worker suffering under the mechanisation of factory production, could be challenged. But even in Morris's workshops, workers undertook repetitive production processes, a practical necessity that seriously undermined the liberating environment he had envisaged (Harrod 1999: 17). The inconsistencies between Morris's ideals and what he was actually able to do, led him to establish the Socialist League in 1885, editing The Commonweal magazine as its voice (Lambourne 1980: 27). He had come to believe that only through a socialist revolution might craft be truly liberated and liberating (ibid: 30 ).

In a more utopian spirit, Charles Ashbee attempted to sidestep capitalism and its associated factory conditions by founding the School and Guild of Handicrafts in 1888. Ultimately this led to a social experiment in which Ashbee relocated one hundred and fifty East-end workers from London to Chipping Campden (Ashbee 1977). Ashbee believed that the Arts and Crafts movement, as he termed it, was part of a three-way revolution in tackling the effects of mechanised industrialisation, working alongside, but not identical to, socialism (ibid: 5-9).

In giving workers back their creative lives, connecting them to their craft and the object of its production, Morris and Ashbee both hoped that other positive changes to living conditions would follow. But the social and economic 
conditions surrounding their projects limited the power of their theories, and they became aware of the danger of creating "....a nursery for luxuries, a hothouse for the production of mere trivialities and useless things for the rich" (ibid: 9). Though both tried to resist this, the generation of a new style that was suggestive of hand production, such as the 'Tudric' and 'Cymric' metal ware ranges, produced by Liberty and Company, commoditised the very notion of hand-making, translating its apparent authenticity into economic value (Lambourne 1980: 65). By naming these wares with historical or indigenous titles, British department stores like Liberty aligned hand-made objects with the 'ethnic' goods, also fashionably used to represent ideals of pre-industrial production. Hand-crafted objects were marketed by their primitivism or their ability to evoke in their consumers, a nostalgia for pre- industrial, pre-colonial societies (Cheang 2007: 2-7).

The early modern school of social anthropology also gained its distinct identity at the height of the modern industrial age. There are strong parallels between its underlying vision and that of a creative life based in craft knowledge as articulated by Pugin, Morris and Ashbee among others. But unlike these thinkers, members of the early modern school of Anthropology shied away from addressing questions of industrialisation directly, turning instead to what they saw as stillexisting sites of pre-industrial life. Focusing on questions of human origins and using technology as a measure of progress, anthropologists like Edward Tylor (1871) and Lewis Henry Morgan (1877), took technology, tool making and the creation of artefacts as indicators of the relative sophistication of any given group. Notwithstanding the geographical distance between themselves and their contemporaries, their vision of material culture as progressive, mirrored that of the arts and crafts movement, both drawing a strong parallel between technology, the production of objects and (ideal) social organisational forms.

Nineteenth century anthropology was enchanted by non-industrial material culture. The categories 'ethnographic' or 'native' art, craft and design, were extended to include many of the objects encountered and collected by anthropologists, and also those gathered by travellers and missionaries. The analysis of these artefacts often overtook any real curiosity about, or engagement with, those who produced them. Objects were seen as representative of culture, but separable from lived experience. The Pitt Rivers museum in Oxford, though now appearing somewhat whimsical with its cabinets of curiosity, reflected, at its inauguration, a modern scientific trend in museology. Designed as a "typology" by its founder Henry Lane Fox (Pitt Rivers), the acquiring, organisation and assessment of objects was arranged in "...a sequence that suggested the possible evolution of a particular class," from primitive to more complex (Smith 2001: 10). Thus the object became a sign for the classification of the society from which it derived.

While the Pitt Rivers museum reveals the depth of the faith placed in objects up until the end of the nineteenth century, the convention of using artefacts to demonstrate typologies had already begun to change. By the beginning of the twentieth century, anthropology's concern for all forms of visual and material 
practice - for example photography, objects, and art - was eclipsed by a new fascination with whatever lay beneath the surface of social life. The study of material objects, and the visual methodologies that had been so central to the early modern discipline, gradually became symbols of something simplistic, even archaic. In the British and US schools of anthropology, explorations of 'invisible' social structures were quickly established as the proper focus of academic interest.

During the early years of the century, a new methodology for anthropology was born. Iconic of what has been called 'the fieldwork revolution', the work of British anthropologist Bronislaw Malinowski emphasised the centrality of being and living in the field. Understood as an immediate experience between the anthropologist and his or her subject, this demanded a different orientation from that appropriate to objects removed from their contexts. It has been argued that Malinowski's emphasis on the fieldworker and their experience was a decisive moment for visual and material practices in anthropology. The subjectivity of fieldworker, exposed to the field like light-sensitive film, - and 'developed' on their return home - soon usurped the place of the photograph as evidence (Pinney 1992:82). This shift from interpreting the circumstances of life through the production and appearance of objects, to a new engagement with 'underlying' structures of lived experience, came to a head in what we have identified as our second 'moment'.

\section{Moment Two}

In British and US anthropology, the study of artefacts alienated from their contexts, alongside the study of making, had all but disappeared during the first half of the twentieth-century. Evolutionary theory was eventually superseded by the development of a new form of cultural analysis. Structuralism, a system of social interpretation derived from the linguistic work of Ferdinand de Saussure, attempted to resolve the difficulties inherent in interpreting the patterns underlying social experience. The focus was on illuminating the invisible, organising structures of societies (langue) - kinship systems, for example. While the actions of structures could still be evidenced through the visible activities and outcomes of rituals and objects (parole) (Tilley 1992: 6-8), two things had now changed. First, all human activity took on potential significance; and second, observable phenomena were not important in themselves but rather as indicators of social patterns which were now seen as the true object of study.

Importantly however, although structuralism and the new science of semiology promoted methods of visual analysis significantly different from those of an earlier, and by now, eclipsed, object-focused period, semiotics and structuralism did allow a belated return to an apparently object-based interpretation of society (Buchli 2002: 9-12). Crucial to this return was that objects ceased to be seen as static visual phenomena and became viewed instead as sites upon which human actions converge. 
By the late 1960s a number of challenges to structuralist conceptions of human life had begun to emerge. Pierre Bourdieu through his work on 'the theory of practice' effectively adapted structuralism in order to address questions of human agency (Margolis 1999: 65-66). Bourdieu shifted emphasis away from organising structures, towards the agency of individual lives and experiences in creating social forms. This 'structuring structure' as Bourdieu termed it, was given the name 'habitus' - a concept that greatly influenced a new generation of anthropologists. The concept allowed human agency to be understood as a force both structured by and generative of the communal organising structures. Objects, rituals, everyday actions and skilled activities were all important elements in this dynamic making and re- making of society. Skilled production thus became one of a number of creative forms of practice and objects that could be viewed as part of a constant process of change. ${ }^{10}$

A similar shift, from static object to object as a site of action, can be seen during this period within craft and design. During the 1950s, 1960s and 1970s, design moved its concern from 'high' modernism to an interest in artefacts, including popular architecture, that were part of the everyday mass-market. Indeed, the very act of designing was now extended to embrace everyday acts. ${ }^{11}$ The idea that skilled practice could encompass ordinary actions and that specialist design knowledge was less important than everyday know-how, was actively pursued by designers. For example, Alison and Peter Smithson worked with the Sugden family to create a bespoke dwelling for their clients, based entirely on the family's patterns of behaviour (Hawkes 1997: 45). Ettore Sottsass' design of the Olivetti Valentine typewriter with Perry King in 1969, was presented as an "anti-machine", capable of reconfiguring the relations between designer and consumer (Labaco 2006: 39). In opposition to industrialisation, the product did not dictate the conditions of its use; rather its purchase, portability and function would allow the consumer to actively re-invent the object according to their own personal needs (Blauvelt 2004: 21). In both instances, it was less the object and more the practice of everyday life that was important, with the ideal relationship between the designers and consumers significantly bypassing the object.

This focus on practice, as a thing in itself, was simultaneously played out in the anti- design movement as well as action painting and sculpting during the 1950s and 1960s. Though these impulses in art, design and craft come from disparate places, they all put the process of interaction centre stage. This frequently resulted in objects that were less about meaning-making than about a perpetual expression of process. Furthermore, this 'process' was not the skilled practice of the past, but evidence of a more general sense of action associated with apparently unskilled activities such as dripping and splashing, or even destructive acts like tearing and ripping (Slivka 1999; Schimmel 1999).

10 See for example Nick Thomas' Entangled Objects: exchange, material culture and colonialism in the Pacific (1991).

11 Victor Papanek championed this approach: "all men are designers ... [d]esign is composing an epic poem, executing a mural, painting a masterpiece... But design is also cleaning and reorganising a desk drawer, pulling an impacted tooth, baking an apple pie..." (1972: 3). 
In his exploration of Abstract Expressionism, a movement in which both artists and craftspeople began to engage directly with materials, using them as an expressive form, Glenn Adamson points to differences in the way the work was received (2007). Abstract work in paint and the development of action painting found a clear acceptance with fine art audiences, while the expressive clay of the Otis group was perceived by many as an aspirational leap from craft to fine art (ibid: 47). Adamson traces this difference in reception, to distinctions between visuality (in fine art) and tactility/sensuality (in craft) (ibid: 49). But what is noteworthy in the context of our discussion here is that action painting effectively bypassed the physical presence of the artwork in favour of a new connection between artist and viewer. In craft on the other hand, despite the genre of the functional ceramic vessel coming under increasing attack, the relationship between artist and audience was less pronounced than in the other fields. The primary exchange continued to be one between material and maker.

Until the end of the nineteenth century, anthropology, art, craft and design each focused attention on the relationship between people and social aspects of production and on the evidence that objects could provide of this. By the mid twentieth century, social and material production had lost their singular association with an activity tied to a product. For anthropology, material and visual culture had already long been eclipsed by a shift towards the hidden structures of social life. During the first part of the twentieth century the art object began to be dissolved as linguistics and semiotic theory influenced these areas. But for craft and design, the focus on objects remained. Designers like Sottsass and the Smithsons began to explore and challenge functionality; and craft too began to consider function more iconically. Still, craft maintained the centrality of the relationship between materials and maker and in the 1960s in particular, it was this attachment to the expressive construction of objects, in opposition to challenges to making in other areas of artistic and industrial production that transformed craft into an important subculture. ${ }^{12}$ Craft retained its presence as 'other' in this respect. But as we shall see, in recent years the alterity of craft has begun to be dissolved.

\section{Contemporary debates about practice}

If our two moments reveal points of divergence and convergence between our four fields, the contemporary call in many fields for more holistic perspectives on human activity in the world have come to influence all four fields in comparable ways. In anthropology, prior to the work of post structuralists such as Bourdieu, the era of the machine along with the alienation of the worker's judgement, personality and creativity influenced the understanding of all forms of making and production. But by the 1980s, substantial numbers of anthropologists were

12 Craft as 'subculture' was quickly absorbed as 1973 saw the highly successful launch of Crafts magazine and of The Craftsman's Art exhibition. During the 1970s the aesthetic of the handmade became central to consumerism. 
working to dismantle the (mechanistic) dualities at the core of the discipline including those between biology and culture, body and mind and individual and society; new perspectives on human- environmental relations now began to come through.

One effect of this was the gradual replacing of the category of technology in anthropology with the idea of skilled practice (Lave 1988; Lave and Wenger 1991; Ingold 2000). In tune with this, anthropologists such as Jackson (1996), Ingold (2000), Stoller (1997) and Taussig (1993) developed phenomenological perspectives on social life that drew new attention to the importance of embodiment and the senses in understanding social worlds. With particular reference to James Gibson, Ingold, for example, developed the concept of a "sentient ecology" (2000: 25), proposing that human beings engage with and are part of the world, not through the dualistic workings of mind and body, culture and nature, but as a "singular locus of creative growth within a continually unfolding field of relationships" (Ingold 2000:4-5). From this perspective, knowledge could be approached not as a matter of mental planning followed by practical testing, but of being, living and engaging practically in the world. In tune with the legacy of 'moment two', life is shown by Ingold to be a matter of 'enskilment', with the very actions of living understood as a type of apprenticeship in which learning is continually undertaken. ${ }^{13}$

The emergence of new phenomenological perspectives in anthropology has been especially significant to those wanting to pursue work that diverges from discursive or 'culturally-constructed' models of social life. One of the questions raised by these newer perspectives is how anthropologists might present innovative and yet accurate explorations of the affective dimensions of experience. It is in part a commitment to this question that has profoundly influenced debates within anthropology about its techniques and representational forms, impacting on the visual practices already sanctioned within film and the museum and allowing for new dialogues between anthropology and contemporary art to emerge.

The benefits to anthropology of engaging with contemporary art's material and sensual practices reside partly in how these might enable anthropologists to extend their own sensory repertoires, better equipping them to approach and represent other cultures (Schneider and Wright 2006:13). But it is also the case that the work of Ingold and others has allowed those committed to the visual in anthropology to challenge certain discourses previously used to interpret such

13 For Ingold, skilled practice has at least five important characteristics: Intentionality and functionality are immanent in the activity itself. Skill is not as Marcel Mauss said, just technique of the body. Rather it is co-ordination of perception and action in a richly structured environment. Skilled practice is not application of mechanical force to exterior objects but requires care, judgment, dexterity (Pye 1968: 22, Ingold 2000: 353).

Skilled practice cannot be reduced to a formula and therefore cannot be due to transmission of formulae. The novice observes other practitioners through his own perceptual engagement with surroundings. Apprenticeship involves practitioners introducing novices into context that afford select opportunities for perception and action. Design does not precede form, rather by bringing perception to environmentally situated action, form is generated. 
work (Grimshaw and Ravetz 2009). Once recognised as more than an adjunct to existing forms of anthropological knowledge, visual practices hold the possibility of different 'ways of speaking and knowing' from those traditionally sanctioned by the field (MacDougall 1998:63).

A small number of anthropologists have begun to explore how anthropological research might be approached as creative practice. In 2005, Wendy Gunn curated the exhibition Fieldnotes and sketchbooks: challenging the boundaries between descriptions and processes of describing. ${ }^{14}$ Rather than setting out to be an exhibition of artistic, architectural or anthropological works, Gunn aimed to reflect upon disciplinary ways of working, knowing and describing. Those who took part were each allotted a wall-mounted cabinet to work within. The research of which the exhibition was part, concluded that art's, anthropology's and architecture's notational forms grow from practitioners' skilled ways of moving through and attending to the world, directing a viewer's attention along those same 'paths' (Gunn 2005).

In the area of museum studies, once dismissed as an archaic hangover from an earlier age, Mary Bouquet has led the way in developing the exhibition as a form of contemporary anthropological practice (2001), something that has influenced younger anthropologists. Alyssa Grossman recently carried out fieldwork in Romania into post-communist memory, looking at the links between memory and material culture. With collaborator and artist Selena Kimball, Grossman produced The Memory Archive at Bucharest Museum. Writing about their work together, Grossman and Kimball describe the tension between their practices, leading them to install Grossman's film of people talking about their memories of significant objects and Kimball's animations of these same objects, on facing screens (2009). Their juxtaposition of anthropological and artistic practice reminds us that the dynamic tensions between social and aesthetic concerns must somehow be negotiated when art and anthropology meet.

The opening out of design from the 1970s also generated new questions about craft as a human practice. As had happened with design, the characteristics of craft practice were re-evaluated particularly during the 1980s and 1990s in Britain. But while function was re-examined and challenged, rather than demoting craft practice as designers had done with design, the critical focus was on what made working with material distinct as a skill. This examination resulted in an analysis akin to Ingold's, where the physical nature of undertaking craft took on terms such as "intelligent making" (Press and Cusworth 1998). This inferred a fluidity of mind and body versus a purely mechanistic understanding of craft as unthinking action. In the ensuing years between moment one and moment two, craft had begun to develop a new relationship with fine art. Where once craft had played the role of liberating practice in the face of industrialisation, it was now viewed as little more than a mechanical activity requiring little thought compared to conceptually driven art forms (Adamson 2007; Veiteberg 2005: 62-87).

14 Aberdeen Art Gallery, 6th April - 4th June 2005 
The notion of craft as unthinking and uncritical was a central concern for Peter Dormer in The Art of the Maker (1994). He deconstructed the prevailing prejudices about craft practice as mechanical, utilitarian, unimaginative, uninterested in aesthetics, rule-based and inhibiting to creativity (1994: 8). But like many writers on craft, Dormer called on Michael Polanyi's writings to establish a new framework for considering and understanding craft practice. This drew attention away from specialised practices and into considerations of how craft practice operates in parallel to the non-formula, flexible, and organic actions and learning within everyday life (1994: 20). The expansion of craft into a broader category has resulted in work more able to explore and critique the relationship between maker and materials rather than defend a philosophical position. Work such as that of Maxine Bristow, Caroline Slotte and Susan Collis examines the conditions of craft in society by implicitly commenting on more focused analyses of skilled practice such as those of David Pye.

Alongside Polanyi, the understanding of workmanship defined by David Pye provided an important legacy for thinking about practice within the craft world. Pye wrote The Nature and Art of Workmanship in 1968 in which he identified a workmanship of certainty and a workmanship of risk - the former that of industrial manufacture, the latter that of craft (1968: 4). However, as design and craft expanded as terms, the opposition of a workmanship of certainty and risk was critically re-examined, providing the core for a conceptual yet very materially-orientated body of work. For some makers, such as the glass artist Keith Cummings, a critical positioning to Pye has emerged through his creation of repeatedly cast objects, parodying the isolation of craft as a skilled practice centred on exquisiteness, singularity and task-orientated labour (Cummings 1989). In aesthetic opposition, but driven by the same focus, the work of Maxine Bristow, Caroline Slotte and Susan Collis derives from a practice of such mechanical repetition (or at least the appearance of it), that the constructed objects teeter perpetually between certainty and risk.

In addition to this individual re-examination of making within craft practice, there has also been a more profound questioning of what actually constitutes craft and design practice. This can be compared with the re-examination of methods in anthropology. A challenge to the ideal of the singular iconic designer has come about through projects that are task centred rather than designer centred. ${ }^{15}$ Collaborative ventures such as The Design Transformation Group (DTG), established in 1995 by Nick Udall, Cristiaan de Groot and Maxwell Young, have focused on the build up of a critical mass of methodologies for creative and critical practice through events (DesignQuests) that encourage active ways of interaction between designers and theorists by "stepping confidently into... play with 'not knowing' (Udall 1997: 1). At these events, design and ways to it can be created from any starting point. ${ }^{16}$ In craft in the 1960 s and 1970 s, collaboration

15 For example, the design collective Droog residency at Oraniebaum in Germany (Williams 1999) and the 'Design Noir' project by Fiona Raby and Antony Dunne. (Rattray 2007).

16 Strategies might include the use of lying, dating a chair, marching through a town on the Isle of Wight, or getting lost. 
and democratisation was an important part of its role as subculture, (though one might argue that it has performed this role at least since Pugin's time). Thus collaboration has not been embraced as a new method to create craft. However, projects such as A field of silver: silver in a field work in a similar way to the events designed by the DTG. The project brought together ten jewellers for a three-day workshop in a field in South Oxfordshire and provided each maker with only a piece of flattened silver by which to create new works. By taking makers out of their familiar environments, the organisers asked participants to re-examine the trusted methods of their own creativity. Inevitably makers called on many more skills -- such as opening a gate or collecting berries -than their identifiable 'skills as makers' might superficially suggest (Anon 2000: 30-31). Other collective projects such as Pixel Raiders have brought together craftspeople utilising digital technologies (Johnson 2002).

It is clear from all these examples that the concerns of craft, design, art and anthropology are being aligned in new ways, due on the one hand to visual practices' embracing of 'the everyday' and the 'invisible'; and on the other to a new 'phenomenological turn' in anthropology that has seen some anthropologists looking again to sensory, visual and material forms. If a new and more expansive idea of practice has allowed these different constituencies to come together, then this has also enabled each field to draw new and closer connections between making, thinking and communicating.

\section{The papers}

As we have seen, fascinating moments of convergence and divergence underpin the contemporary interest in 'practice'. Although it is tempting to imagine that migrations between the fields of art, anthropology, craft and design have only happened recently, it's clear that they have shared significant ways of thinking about human action, culture and the material world. The five papers presented here expand on this historical legacy, showing that as with other forms of migration, movement between disciplines can be intentionally sought after and prepared for, or unexpectedly encountered. The circumstances that attend such movements often indicate something of the underlying assumptions that drive practices within anthropology, art, craft and design.

The first two contributors to Migratory Practices to be discussed here demonstrate the rich results that arise from transplanting making into the realm of curatorial and museum practice. These papers examine the potential interplay between artistic practice and curating from both an artist's and a curator's standpoint and are the result of both participants identifying the need for exchange across disciplines. However, this awareness and acceptance of the requirements of migration does not result in the papers relaying a seamless or necessarily easy experience. Rather these papers indicate what occurs when disciplines have developed with mutual aims and some exchange of methods and when practice begins from a relatively developed starting point. As we shall see, particularly in 
the second of the two papers from Emma Martin, advancing a new position that attempts to incorporate the mixed history of interchange between disciplines is not easily translated to the level of institutional practice.

Caroline Bartlett's paper discusses archives of texts and textiles that she has worked with as an artist over the last nine years. Bartlett's attention to materials has led to a focus on the tensions between individually meaningful and publicly memorable objects. In one poignant example she tracks the shift in status of a personally meaningful object to one that has become almost historically meaningless. On its first appearance in the archive of Sir Richard Burton at Orleans House, an envelope full of pressed flowers was labelled "the last flowers that my darling culled the day before his death", a touching and emotional acquisition. However, Bartlett notes how over time and through decomposition, the label is transformed to "an envelope containing a few small brown fragments". Here the artist identifies how the loss of individual agency as a means to understand this object, has profoundly changed the meaning and power of the object.

By thinking through materials and their manipulation as a whole, Bartlett is able to expose the subtle and underlying ways in which archives are constructed. As a practitioner in textiles she not only evokes the history of objects, but the inhabited world of the conservator. In a series of detailed photographs, the artist examines the intricate work of these professionals. By focussing on the hands alone, she reveals how the tacit understanding of cloth and its preservation informs critical decisions and silently shapes how history is recorded. As with the painstaking practice of Bristow et al, the conservator works to produce results, the ultimate aim of which is their invisibility. Yet like these contemporary artists, the work is no less critically significant.

The relationship between the object, classification and the curator is also examined in Emma Martin's paper. Martin has been curating the South Asian collections for National Museums Liverpool (NML) for over a decade. Her experience, and the very physical ordering of the status of the museums in Liverpool with the fine art collection (top of the hill), seen in isolation from the ethnography collection (bottom of the hill), demonstrates how the impact of colonial history is still huge within the organisational structures governing knowledge and history. In her paper Martin argues how by being open to creative practice undertaken in South Asia, it becomes possible to challenge the established and bigoted classification of skills and materials in British museums. By discussing the isolation of the sculptor Sonabai Rajawar and her experimentation with traditional artistic practice, Martin reveals how the actual circumstances of production in a small village in India have led to large changes in the infrastructure of NML. Martin demonstrates how categorical terms such as 'art' and 'ethnology' have provided the basic division for the museum collections she works with. These, she argues are inadequate to communicate the realities and complexities of skilled practice and everyday experience. 
In these two papers it is the practice of making that has provided either the illumination of, or the challenge to, traditional historical and ethnographic classifications within museums. The inclusion of Rajawar challenges the opposition of art and craft, innovation and tradition that has dogged the split between (literally) 'high' art and 'low' craft in Liverpool. Bartlett's ethnographic study of archivists and conservators, entitled the Bodies of Knowledge series and purchased by the Victoria and Albert museum in London ( $V$ and $A$ ), has similarly challenged the $V$ and A's institutionally-established collection boundaries.

As has been noted, migratory practice is not always something that is chosen or anticipated and the second group of contributors to this collection - Kay Lawrence, Stephen Dixon and Hamid van Koten - describe projects that have resulted in a reflection on personal philosophical positions and ethical difficulties of migration. A consideration of these papers can also be used to indicate the status of migratory relationships across different disciplines. Many, like artistic practice and ethnographic work or oral history, have a relatively underdeveloped association.

Kay Lawrence is a non-Indigenous Australian textile artist and lecturer who discusses a collaborative project Weaving the Murray, undertaken to celebrate the Centenary of the Federation of Australia. Intended to bring together artists from indigenous and non-indigenous communities, Lawrence explores the difficulties in this type of collaboration. Interviewing most members some years after the end of the project, she is able to deconstruct the experience of creating this multi-media art work within a concentrated and pressured period of time, noting the many areas in which misunderstandings took place, as well as moments of positive productivity. Lawrence notes that for the formally educated non-Indigenous artists, the intention to construct a conceptually-driven finished textile art work veiled unacknowledged assumptions. For the indigenous artists however, some of whom were educated both through a formal system and in the family tradition, assumptions were about processes of collaboration and the personal qualities of practice required to construct the various pieces. This opposition of motives and expectations resulted in the sense of ownership between the parts of the finished piece being divided and contentious, alienating even to the present day at least one of the Indigenous artists.

Australia is also the site for Stephen Dixon's paper. Dixon is a British ceramicist who was engaged on a three-month residency (through the HAT2 scheme) in Melbourne, Australia in order to challenge his own preconceptions about craft. However, he found the colonial history of Australia and the present experiences of place in both indigenous and non-indigenous contemporary society complex and difficult - his own position problematic. Dixon's typical role when constructing work in Britain is that of a social commentator, a satirist, but in Australia the intimacy with which the artist understands and inhabits contemporary British social politics was lost. As such he instinctively began to create work that centred on narratives of migration itself - convict love tokens, and the myths and migrating material history of Captain Cook. The works began to explore the penal system, the stories of Ned Kellly, and the bureaucracy that symbolised the 
power of colonialism, with his own position as author purposefully clouded - his imagery multi-layered and graphically contested. At times this visual confusion is overt with image, text and mark laid on top of each other, vying for authority and space. At other times it is hidden - the surfaces seem minimal, yet it is the materials themselves that provide the story of contested place. Dixon uses his practice as a critical tool for expressing the complexities of place, identity and migration and crucially the role of the artist in relation to these.

Though geographically far removed, the contribution by Hamid van Koten who is an industrial designer, draws on similar themes of transience and movement. In his contribution for the collection he tells of the reconsideration of his own design practice through an engagement with people and place. Working on a large community project in Ullapool, a small fishing village on the east coast of Scotland, van Koten began to see that the experience of the habitual, tidal rhythms of the community could be translated into communal architecture and furniture that enhanced the perception of the local community who inhabited the transient landscape. Ullapool seemed initially to constantly shift its identity, yet as van Koten realised, it was this change that also provided its stability and cohesion. In the work he produced, he felt he had enabled the community to visually and materially express their poetic existence. In his paper for this collection, van Koten opposes this 'sympathetic' process with the cynicism that has come to pervade much of contemporary design practice. He outlines how ethnographic techniques are being used to boost economically-driven cycles of consumption, rather than enhancing human social experience.

All three papers demonstrate the realities of migration. Challenging one's own practice by taking on different projects, or journeying to new locations, is not always a matter of choice and can bring unexpected difficulties for which we may be ill-equipped. Yet all three reflections demonstrate how venturing into new philosophical and geographical territories can provide important opportunities to reflect on the understanding of our own theoretical positions and skills. Furthermore, that in recording and analysing these experiences, one begins to establish a critical identity for this form of migration for others to build on.

\section{Conclusion}

In seeking a context for the Migratory Practices collection, we have recounted something of our personal motivation, of the historical background to contemporary discourses of 'practice', and of contemporary points of connection between anthropology, art, craft and design.

Though all four disciplines have been involved in considering what we now term questions of practice, the focus for each was once object centred - a way of forging the construction of a discipline, design movement or craft genre. This earlier emphasis on stasis and objects is being transformed however through the current emphasis on the fluidity of social and material processes. Yet this 
has not resulted in a loss of identity for disciplines, but rather as Tim Ingold noted in his keynote paper for the conference, revealed them to be continuous with everyday life, able to work alongside one another. In effect, like the status of objects described in moment two, anthropology, art, craft and design could now be approached as excitingly entangled, unfinished and unresolved ways of knowing the world.

Rather than being seen as interdisciplinary models for the future however, these papers offer us something more modest: a glimpse of what happens when those from disciplines we tend to assume operate through mostly different textual/visual/material registers, actually report on what they do. The title of this introduction uses the phrase the 'impossible place', (originally used by Walter Benjamin and quoted by Hal Foster in his essay about the artist as ethnographer in 1996). This raises the possibility that migrations between anthropology and arts practice might lead to something of an ethical, aesthetic or intellectual dead end. Yet the image of an impossible place might also be a suitable metaphor for what these papers reveal. If viewed as a closed, merged and finished object, the image of place contradicts the open-ended, and often imperfect, ways of living and engaging with people, places, stories, events and institutions that these reports evoke. But if place is understood as event, as gathering, the impossibility is to consider place/field/discipline as something impermeable, something that does not have inward and outward flow.

As we noted above, our initial goal was to include craft and design within the more established debate between anthropology and art. In doing so we have not wanted to pin down what craft, design, anthropology or art can or should be, while also attempting to acknowledge what they individually offer. But it is perhaps appropriate to finish by reflecting briefly on the benefits of allowing craft and design to enter the art/anthropology dialogue. In constructing our two moments around what is now called practice, we noted that craft, more than design, has sustained a continuous relationship between maker and material, not diluting this intimacy in favour of a newly pronounced connection between artist or designer as conceptualiser and audience. Craft has often been considered rather naïve for retaining its interest in the material, but a new theoretical interest in craft suggests it may be this very quality that has finally let it back in from the cold. ${ }^{17}$ Jorunn Veiteberg identifies the intimate connection between craft and materials: "Craft insists on the physical dimension more than other art practices (2005:33) she writes. She then quotes Linda Sandino on the importance of materiality itself: "...if matter matters, then it is the best place to locate an exploration of our relationship, not only with things themselves, but also to the materiality of those things (2005: 33).

It is this very insistence on the fundamental relationship between maker and material that we believe makes craft so pertinent to the contemporary debate between anthropology and art. While, through moment two, art, anthropology and design eroded the 'thing in itself', treating material as a surface for

17 For example The Journal of Modern Craft and Textile, both published by Berg. 
the projection of some other concept or meaning, craft held firm. Later, anthropologists and sociologists came back to the material world, this time folding into it an investigation of enskilment, creativity and practice - and a new interest in things - not as sites of meaning, but as meanings in themselves (Henare et al 2007). Thus craft, in its maintenance of the centrality of material itself, has taken on a new and perhaps unexpected relevance. In turn, this has allowed crafts practitioners some freedom to critically explore in material ways, their own and others' contexts for practice, rather than having to defend their position. As Adamson has so astutely commented "...craft is not a defined practice but a way of thinking through practices of all kinds"(2007: 7).

\section{Acknowledgements}

We would like to acknowledge the generous contribution of all those who presented papers and acted as discussants at the original Migratory Practices conference: Caroline Bartlett, Stephanie Bunn, Mary Butcher, Stephen Dixon, Carine Durand, Helga Gamboa, Tim Ingold, Andrew Irving, Kay Lawrence, Raymond Lucas, Sharon MacDonald, Emma Martin, Anne Morrell, Judith Palmer, Jeremy Theophilus, Roy Villevoye, Moira Vincentelli, Hamid van Koten. We are grateful to Anna Grimshaw for her critical reading of an earlier version of this essay. The conference programme and the research for this essay were made possible through the generous financial support of MIRIAD, MMU and the Arts and Humanities Research Council/UK. Thanks must also go to A Fine Line who commissioned Jane Webb to expand the critical debate surrounding the HAT2 project. Any omissions or inaccuracies remain the responsibility of the authors.

\section{Bibliography}

Adamson, G., 2007. Thinking Through Craft. Oxford; New York: Berg.

Ahmed, S. et al., 2003. Uprootings/regroundings: questions of home and migration. Oxford; New York: Berg

Anon., 2000. A field of silver: silver in a field. In Crafts. London: Crafts Council.

Ashbee, C. R., 1977. Craftsmanship in Competitive Industry. London; New York: Garland Publishing. Attfield, J.,1999. Beyond the Pale: Reviewing the Relationship between Material Culture and Design History. Journal of Design History, 12(4),pp. 373-380

Blauvelt, A., 2004. Strangely Familiar: design and everyday life. Minneapolis, Minnesota: Walker Art Center. 
Bouquet, M., 2001. Academic Anthropology and the Museum: back to the future. Oxford: Berghahn. Buchli, V., 2002. Introduction. In V.Buchli, ed. The Material Culture Reader. Oxford; New York:

Berg. Cheang, S.,2007. Selling China: Class, Gender and Orientalism in the Department Store. Journal of Design History, 20(1) pp.1-16.

Cummings, K., 1989. (inpress) Craft: The Workmanship of Risk, Certainty and Opportunity.

Dormer, P.,1994. The Art of the Maker. London: Thames and Hudson.

Foster, H.,1996. 'The Artist as Ethnographer'. In The return of the real. Cambridge, Massachusetts; London, England: MIT Press

Grimshaw, A., 2001. The Ethnographer's Eye. Cambridge, UK: Cambridge University Press.

Grimshaw, A. \& Ravetz, A., 2005.Visualizing Anthropology. Bristol: Intellect Books. Grimshaw, A. \& Ravetz, A., 2009. Rethinking Observational Cinema. Journal of the Royal Anthropological Institute. 15( 3), pp 538-556.

Grossman, A. \& Kimball, S., 2009. The Memory Archive: Filmic Collaborations in Art and Anthropology. in Reconstruction 9.1: Fieldwork and Interdisciplinary Research. http://reconstruction.eserver.org/091/contents091.shtml Last accessed August 3rd 2009

Gunn,W. ed., 2009. Fieldnotes and sketchbooks: challenging the boundaries between descriptions andprocesses of describing. Hamburg: Peter Lang.

Hawkes, D., 1997. A celebration of domestic life. The Architects' Journal. (205), pp. $45-50$.

Harrod, T., 1999. The Crafts in Britain in the Twentieth-Century. Bard Graduate Center for Studies in the Decorative Arts: Yale University Press.

Henare, A. et. al., 2007. Thinking Through Things: theorising artefacts ethnographically. London and New York: Routledge

Highmore, B. (ed.) 2002. The Everyday Life Reader. London: Routledge.

Ingold, T., 2000. The Perception of the Environment: essays in livelihood, dwelling and skill. London/New York: Routledge.

Anthropology is NOT Ethnography Radcliffe-Brown Lecture 2007

Jackson, M., 1996. Things As They Are: New Directions in Phenomenological Anthropology. Bloomington and Indianapolis: Indiana University Press.

Johnson, P., 2002. “Technology Talks”. Crafts no. 176, May/June, p. 65. 
craft + design enquiry

Labaco, R. T., 2006. "Humanist for the Modern Age" in Labaco, R. T. (ed.) Ettore Sottsass: architect and designer. London/New York: Merrell.

Lambourne, L. , 1980. Utopian Craftsmen: The Arts and Crafts Movement from the Cotswolds to Chicago. London: Astragal Books.

Lave, J., 1988. Cognition in practice: Mind, mathematics and culture in everyday life. Cambridge, UK: Cambridge University Press.

Lave, Jean and Etienne Wenger., 1991. Situated Learning: Legitimate Peripheral Participation.

Cambridge: Cambridge University Press.

MacDougall, D., 1998. Transcultural Cinema. Princeton, NJ: Princeton University Press.

Marcus, G.E. and Michael Fischer, 1986. Anthropology as cultural critique: an experimental moment in the human sciences. Chicago: Chicago University Press

Marcus, G.E and Fred Myers (eds.)(1996) The Traffic in Culture: refiguring art and anthropology.

Berkeley: London: University of California Press

Margolis, J., 1999. "Pierre Bourdieu: Habitus and the Logic of Practice" in Shusterman, R. (ed.)

Bourdieu: A critical reader. London: Blackwell Publishers.

Morgan, L.H. [1877], 1978. Ancient Society. New York: Labor Press

Pinney, C., 1992. 'The parallel histories of anthropology and photography'. In E.Edwards (ed.)

Anthropology and Photography (New Haven and London:Yale University Press)

Press, M. and A. Cusworth (eds.), 1998. "New Lives in the Making". Sheffield Hallam University Learning Research Programme. April.

Pugin, A. W. N., 1969. Contrasts. With an introduction by H. R. Hitchcock. New York: Humanities Press/Leicester University Press.

Pye, D., 1968. The Nature and Art of Workmanship. Cambridge: Cambridge University Press.

Rattray, F., 2007. "On the Contrary”. ID v. 54, no. 3 May, p. 22.

Ravetz, A., 2008. 'Convivere (To Live Together). In Roy Villevoye Detours. Rotterdam: Museum Boijmans van Beuningen. pp. 39-50 
Schimmel, P., 1999. "Leap into the Void: Performance and the Object" in Out of Actions between Performance and the object 1949-1979. London: Thames and Hudson.

Schneider, A.and C. Wright, 2006. Contemporary Art and Anthropology Oxford; New York: Berg Slivka, R., 1999. "The Dynamics of Destruction". Art in America Jan. no. 1, pp. 84-89.

Smith, D., 2001. "Evolution and Culture: the Pitt Rivers Museum, Oxford". Things 14, Summer, pp. 9-24.

Stoller, P., 1997. Sensuous Scholarship. Philadelphia: University of Pennsylvania Press

Taussig, M., 1993. Mimesis and Alterity: A Particular History of the Senses. New York and London: Routledge

Tilley, C., 1992. "Claude Lévi-Strauss: Structuralism and Beyond" in Tilley C. (ed.) Reading Material

Culture Oxford/Cambridge, Mass.: Blackwell.

Tylor, E. [1871], 1920. Primitive Culture, J.P. Putnam's Sons, New York.

Udall, N. (ed.), 1997. Closing the Gap between Subject + Object. Design Transformation Group. Veiteberg, J., 2005. Craft in Transition. Trans. Douglas Ferguson. Bergen: Bergen National Academy of the Arts).

Williams, G., 1999. "The new vernacular”. Blueprint no. 162 June, pp. 26-28. 